\title{
Caracterização morfológica de espécies de Hemerobius Linnaeus, 1758 (Neuroptera, Hemerobiidae) associadas a cultivos de café (Coffea arabica L.), milho (Zea mays L.) e erva-mate (Ilex paraguariensis St. Hill.)
}

Rogéria Inês Rosa Lara ${ }^{1}$

Sérgio de Freitas ${ }^{2}$

\begin{abstract}
Aвstract. Morphologic characterization of the Hemerobius Linnaeus, 1758 species (Neuroptera, Hemerobiidae) associated to the cultivations of coffee (Coffea arabica L.), maize (Zea mays L.) and mate (Ilex paraguariensis St. Hill.). The predators were collected in mate crop in Cascavel and São Mateus do Sul, Paraná, Brazil and some other additional specimens in coffee and maize crops in Ribeirão Preto, São Paulo, Brazil. Illustrations obtained by SEM are given by the first time to the principal structures. Three species of Hemerobius were identified: $H$. bolivari Banks, 1910; H. domingensis Banks, 1941 and H. gaitoi Monserrat, 1996. H. domingensis is recorded for the first time to Brazil.
\end{abstract}

Keywords. Brazil; Hemerobiidae; Hemerobiinae; morphology.

\section{INTRODUÇÃO}

O gênero Hemerobius Linnaeus, 1758, registrado em todos os continentes à exceção da Antártida, congrega cerca de 131 espécies descritas e é o maior da família Hemerobiidae, com 50 espécies citadas para o continente americano (MONSERRAT 1996) e cinco para o Brasil: H. bolivari Banks, 1910, H. cixiiformis Gerstaecker, 1888, H. frontalis Navás, 1932, H. gaitoi Monserrat, 1996 e H. lentus Hagen, 1861 (MonserRat 1990, 1996).

Os primeiros trabalhos taxonômicos desse gênero discriminavam as espécies a partir de caracteres como a coloração e a venação das asas que demonstraram ser insuficientes para a correta identificação específica. Tais caracteres foram utilizados até a descoberta do valor taxonômico da genitália do macho, utilizada por CARPENTER (1940), KEVAN \& KlimasZewski (1987) e MonserRat (1996) em suas revisões para o continente americano.

MonserRat (1996) ao revisar as espécies neotropicais de Hemerobius propôs a divisão do gênero em quatro grupos de espécies: albipennis, bolivari, stenopterus e withycombei. As espécies aqui caracterizadas pertencem ao grupo bolivari que, segundo MonSERRAT (1996), é o mais heterogêneo e abriga dez espécies: H. bolivari Banks, 1910, H. centralis Navás, 1913, H. chilensis Nakahara, 1965, H. cubanus Banks, 1930, $H$. domingensis Banks, 1941, $H$. exceptatus Nakahara, 1965, $H$. gaitoi Monserrat, 1996, H. hernandezi Monserrat, 1996, $H$. jucundus Navás, 1927 e H. nigridorsus Monserrat, 1996.

Espécies de Hemerobius associadas a pragas agrícolas, principalmente em frutíferas, foram relatadas por SzABó \& SZEnTKirÁlyi (1981), González Olazo (1987), Santos RoJo \& Marcos-Garcia (1998) e Stetzl \& Devetak (1999) em diversos países.

No Brasil, o conhecimento das espécies de Hemerobius ainda é incipiente e restrito aos trabalhos de Chagas et al. (1982) que relataram a presença de Hemerobius sp. em cultivos de citros e de Penny \& Monserrat (1983) que redescreveram H. hageni (Navás, 1918), da região Amazônica, posteriormente sinonimizada com H. bolivari Banks, 1910 (MONSERRAT 1996). A escassez de conhecimentos sobre o gênero Hemerobius no Brasil ressalta a necessidade de novas coletas em cultivos agrícolas tendo em vista ampliar as informações sobre a biologia e distribuição geográfica destas espécies. Assim, o objetivo deste estudo foi identificar as espécies de Hemerobius associadas a cultivos agrícolas e fornecer parâmetros

1. Agência Paulista de Tecnologia dos Agronegócios - APTA, Pólo Regional de Desenvolvimento Tecnológico dos Agronegócios do Centro Leste. Rua Peru, 1472-A, 14075-310 Ribeirão Preto-SP, Brasil. Endereço eletrônico: rirlara.ddd@apta.sp.gov.br

2. Departamento de Fitossanidade, Faculdade de Ciências Agrárias e Veterinárias, Universidade Estadual Paulista. Via de Acesso Prof. Paulo Donato Castellane s/n, 14884-900 Jaboticabal-SP, Brasil. Endereço eletrônico: serfre@fcav.unesp.br 
morfológicos definidos para o seu reconhecimento.

\section{MATERIAL E MÉTODOS}

Foram estudados 13 exemplares de Hemerobius, dos quais 10 são provenientes da coleção do Departamento de Fitossanidade da Faculdade de Ciências Agrárias e Veterinárias, UNESP, Jaboticabal, São Paulo e obtidos em cultivos de erva-mate e no Campus daquela instituição. Três exemplares foram coletados em cultivos de café e milho, em Ribeirão Preto (SP), por meio de duas armadilhas de Moericke adaptadas (PERIOTo et al. 2000) e industrializada pela Copobrás (modelo PRF-Y), fixadas em estacas de madeira com auxílio de aros de arame a 0,5 e 1,0 m de altura do solo.

Para as mensurações, utilizou-se microscópio estereoscópico equipado com ocular micrométrica de $1 \mathrm{~cm} / 100$ divisões, tomando-se a maior distância na estrutura morfológica a ser medida. Cabeça (Fig. 4), em vista frontal: largura (lc) entre as margens externas dos olhos; largura dos olhos (lo) entre as margens interna e externa, e altura dos olhos (ao) entre as margens inferior e superior do olho. Antena: largura do escapo (le) entre as margens laterais, tomadas perpendicularmente ao eixo do comprimento do articulo e comprimento do escapo (ce) entre as margens basal e apical. Tórax, em vista dorsal: comprimento do protórax (cp) entre as margens anterior e posterior do pronoto, e largura do protórax (lp) entre as margens laterais do pronoto. Pernas: comprimento da procoxa (срc) entre as margens basal e apical; comprimento do fêmur (cf) entre as margens basal e apical e comprimento da tíbia (ct) entre as margens basal e apical. Asas: comprimento da asa (ca) entre a base e seu ponto apical; largura da asa (la) entre as margens anterior e posterior, e largura da área costal (ac) entre as veias costal e subcostal.

As genitálias foram preparadas para dissecação através de maceração a quente em solução de hidróxido de potássio $(\mathrm{KOH})$ a $10 \%$ por 10 minutos, neutralizadas em ácido acético a 10\%, enxaguadas em água destilada e, quando necessário, coradas com Clorazol Negro a 1\%. Para a observação das genitálias utilizou-se microscópio óptico e as ilustrações foram feitas com auxílio de câmara clara.

As estruturas fotografadas em microscópio eletrônico de varredura JEOL, JSM 5410, operado a $15 \mathrm{kV}$, em aumentos variados, foram desidratadas em bateria de álcool etílico de 80 a $100 \%$, durante 20 minutos em cada solução e recobertas por uma camada de $35 \mathrm{~nm}$ de ouro.

Foi utilizada a nomenclatura de CARPENTER (1940) para a venação das asas e a terminologia de TJEDER $(1954,1961)$ e MONSERRAT (1996) para a descrição das genitálias.

Os exemplares estudados estão depositados nas coleções do Instituto Biológico, São Paulo (IBSP) e do Departamento de Fitossanidade da Faculdade de Ciências Agrárias e Veterinárias da UNESP, Campus de Jaboticabal - SP (UNESP).

\section{RESULTADOS}

Grupo bolivari
Hemerobius bolivari Banks, 1910

(Figs. 1, 4-9)

Coloração (Fig. 1). Cabeça, vértice e dorso torácico com faixa meso-longitudinal amarelo-palha, marrom lateralmente; genas marrons; palpos maxilares e labiais amarelo-palha, sombreados de marrom, exceto o $5^{\circ}$ palpômero maxilar e o $3^{\circ}$ palpômero labial que são marrons com a extremidade apical amarelo-palha; antenas e pernas amarelo-palha. Olhos escuros, com reflexos metálicos. Asas anteriores hialinas; veias longitudinais amarelo-palha intercaladas por áreas de coloração marrom; veias transversais sc-r, mp-cu1 e cu1-cu2 marrons; séries gradiformes marrom-claro; pterostigma indistinto. Asas posteriores hialinas; veias longitudinais amarelo-palha; séries gradiformes marrom-claro e pterostigma amarelado.

Cabeça. 4,3 vezes mais larga que a largura do olho (lc/lo), marcada pelas suturas frontogenal, clípeogenal e transtorular. Vértice convexo, coberto anteriormente por microtríquias e com longas cerdas esparsas. Olhos proeminentes, hemisféricos, 2,4 vezes mais longos que largos (ao/lo). Ocelos ausentes. Antenas moniliformes; escapo achatado, 1,2 vezes mais longo que largo (ce/le); flagelo com cerdas curtas, abundantes. Orifício tentorial anterior visível na intersecção das suturas frontogenal e clípeogenal. Labro com margens látero-dorsais arredondadas. Genas lisas, com cerdas esparsas; margem distal da fronte com um par de longas cerdas. Clípeo com dois pares de longas cerdas na margem distal e uma cerda sagital na região central (Fig. 5). Mandíbulas assimétricas, a direita com projeção na margem interna, a esquerda com dente pronunciado na mesma margem. Palpo maxilar com cinco artículos, o quinto fusiforme, com extremidade apical afilada (Fig. 6); os demais, simples com cerdas longas, esparsas; gálea bi-articulada, artículo distal com pilosidade densa, curta; região apical da lacínia densamente pilosa. Palpo labial com três artículos, palpômeros simples, com cerdas longas e esparsas, exceto o terceiro que é semelhante ao quinto palpômero maxilar.

Tórax. Arqueado em vista lateral, coberto por microtríquias; pronoto e mesonoto densamente cobertos por cerdas longas; esparsas na pleura. Protórax: pronoto 1,4 vezes mais largo que longo (lp/cp), com margens laterais arredondadas que cobrem parte dos escleritos laterais. Mesotórax: mesoscuto deprimido na região mediana. Metatórax: metascuto grande e transverso. Pernas com pilosidade densa e curta; procoxa alongada, cilíndrica, 0,8 vezes o comprimento do profêmur (cpc/cf); mesoe metacoxas curtas e cônicas; comprimento dos fêmures e tíbias semelhantes, à exceção do metafêmur que apresenta comprimento 0,6 vezes o da metatíbia (cf/ct); tíbia anterior com um esporão apical; tíbias mediana e posterior com dois esporões; tarsos pentâmeros, pré-tarso com um par de garras laterais e um empódio mediano, em forma de almofada. Asas anteriores e posteriores com macrotríquias sobre as veias longitudinais, transversais da área costal e nas margens; membrana densamente coberta por microtríquias. Asa anterior (Fig. 7): 2,3 vezes mais longa que larga (caa/laa); área costal proximal ampla, 0,3 vezes a largura máxima da asa (ac/laa); veia umeral recorrente definida; $14-16$ veias transversais costais na 
metade proximal, bifurcadas; uma veia transversal sc-r preestigmal; radial e setor radial em tronco único (R+Rs) com três ramos; duas séries gradiformes (três internas e seis externas); medial (M) unida basalmente à radial; medial posterior (MP) unida à cubital 1 (Cu1) por uma veia oblíqua, curta; duas veias transversais mp-cu1 localizadas apicalmente a esta fusão; mp-cu1 e cu1-cu2 não coincidentes, próximas; célula cubital aberta; três veias anais (A) ramificadas; lóbulo jugal distinto. Asa posterior (Fig. 8): 0,8 vezes o comprimento da anterior (cap/caa), 2,7 vezes mais longa que larga (cap/lap); área costal reduzida com veias transversais simples; subcostal espessa; $R$ e Rs não coalescentes, tocando-se por meio de uma veia transversal; duas séries gradiformes (duas internas e cinco externas); medial anterior (MA) unida à radial por uma transversal oblíqua.

Genitália feminina (Fig. 9). Nono esternito, nono e décimo tergitos cobertos por microtríquias, com cerdas longas, esparsas, em maior número nas margens posteriores e ventrais, inseridas em pequenas protuberâncias do tegumento; nono tergito estendido posteroventralmente, com margem posterior sinuosa; nono esternito (gonapófises laterais) ovóide, ectoprocto ovóide, sem projeções; callum cerci com 18 tricobótrias; décimo esternito ausente.

Comentários. Os exemplares estudados apresentaram pequena variação na coloração da cabeça, tórax e asas. MonserRAT (1996) relatou que a maior parte dos exemplares estudados possuía as veias mp-cu1 e cu1-cu2 coincidentes e as fêmeas apresentaram callum cerci com 12-14 tricobótrias. As estruturas da genitália masculina do material examinado foram danificadas durante a preparação do material para microscopia eletrônica.

Hemerobius bolivari é a espécie Neotropical que apresenta maior distribuição, com citações de ocorrência para Guatemala, Costa Rica, Panamá, Colômbia, Venezuela, Equador, Peru, Bolívia, Chile, Brasil, Paraguai, Argentina e Uruguai (MONSERRAT 1996).

Material examinado. BRASIL. São Paulo: Jaboticabal, 1 fêmea, VI. 1995, R.S. Ferreira (UNESP); Monte Alto, 1 macho, 6.IX.2000, C.N. Belelli (UNESP); Ribeirão Preto, 1 fêmea, 3.I.2002, R.I.R. Lara (IBSP); Paraná: São Mateus do Sul, 1 fêmea, 17.XI.1999, M.S.P. Leite (UNESP).

Hemerobius domingensis Banks, 1941

(Figs. 2, 10-17)

Coloração (Fig. 2). Cabeça, vértice e dorso torácico com faixa meso-longitudinal amarelo-palha, marrom lateralmente; genas marrons; palpos maxilares e labiais amarelo-palha, sombreados de marrom, exceto o $5^{\circ}$ palpômero maxilar e $3^{\circ}$ palpômero labial que são marrons, com a extremidade apical amarelo-palha; antenas e pernas amarelo-palha. Olhos escuros, com reflexos metálicos. Asas anteriores hialinas; veias longitudinais amarelo-palha intercaladas por áreas de coloração marrom; séries gradiformes marrom-claro; veias transversais sc-r, mp-cu1 e cu1-cu2 marrons; pterostigma indistinto. Asas posteriores hialinas; veias longitudinais amarelo-palha intercaladas por áreas de coloração marrom; séries gradiformes marrom-claro; pterostigma amarelado. Abdome amarelo-palha, exceto as margens látero-dorsais que são sombreadas de marrom.

Cabeça. 6,0 vezes mais larga que a largura do olho (lc/lo), marcada pelas suturas frontogenal, clípeogenal e transtorular. Vértice convexo, coberto anteriormente por microtríquias e com longas cerdas esparsas. Olhos proeminentes, hemisféricos, 2,9 vezes mais longos que largos (ao/lo). Ocelos ausentes. Antenas moniliformes; escapo achatado, 1,2 vezes mais longo que largo (ce/le); flagelo com cerdas abundantes, curtas. Orifício tentorial anterior visível na intersecção das suturas frontogenal e clípeogenal. Labro com margens laterodorsais arredondadas. Genas lisas, com cerdas esparsas; margem distal da fronte com um par de longas cerdas. Clípeo com dois pares de longas cerdas na margem distal e uma cerda sagital na região central. Mandíbulas assimétricas. Palpo maxilar com cinco artículos, o quinto fusiforme com extremidade apical afilada, os demais, simples com cerdas longas, esparsas; gálea bi-articulada, artículo distal com pilosidade densa, curta; região apical da lacínia densamente pilosa. Palpo labial com três artículos, palpômeros simples, com cerdas longas e esparsas, exceto o terceiro que é semelhante ao quinto palpômero maxilar.

Tórax. Arqueado em vista lateral, coberto por microtríquias; pronoto e mesonoto densamente cobertos por cerdas longas; esparsas na pleura. Protórax: pronoto 2,5 vezes mais largo que longo (lp/cp), com margens laterais arredondadas que cobrem parte dos escleritos laterais. Mesotórax: mesoscuto deprimido na região mediana. Metatórax: metascuto grande e transverso. Pernas com pilosidade densa e curta; procoxa alongada, cilíndrica; meso- e metacoxas curtas e cônicas; comprimento dos fêmures e tíbias semelhantes, à exceção do metafêmur que apresenta comprimento 0,6 vezes o da metatíbia (cf/ct); tíbia anterior com um esporão apical; tíbias mediana e posterior com dois esporões; tarsos pentâmeros, pré-tarso com um par de garras laterais e um empódio mediano, em forma de almofada. Asas anteriores e posteriores com macrotríquias sobre as veias longitudinais, transversais da área costal e nas margens; membrana densamente coberta por microtríquias. Asa anterior (Fig. 10) 2,3 vezes mais longa que larga (caa/laa); área costal proximal ampla, 0,3 vezes a largura máxima da asa (ac/laa); veia umeral recorrente definida; $11-14$ veias transversais costais na metade proximal, bifurcadas; uma veia transversal sc-r preestigmal; $\mathrm{R}$ e Rs em tronco único ( $\mathrm{R}+\mathrm{Rs}$ ) com três ramos; duas séries gradiformes (três internas e seis externas); $M$ unida basalmente à R; MP unida à Cu1 por uma veia oblíqua, curta; duas veias transversais mp-cu1 localizadas apicalmente a esta fusão; mp-cu1 e cu1-cu2 não coincidentes, próximas; célula cubital aberta; três veias anais ramificadas; lóbulo jugal distinto. Asa posterior (Fig. 11) 0,8 vezes o comprimento da anterior (cap/caa), 2,7 vezes mais longa que larga (cap/lap); área costal reduzida com veias transversais simples; subcostal espessa; Rs e R não coalescentes, tocando-se por meio de uma veia transversal; duas séries gradiformes (duas internas e cinco externas); MA unida à R por uma transversal oblíqua.

Abdome. Tergitos e esternitos transversos; nono esternito, 

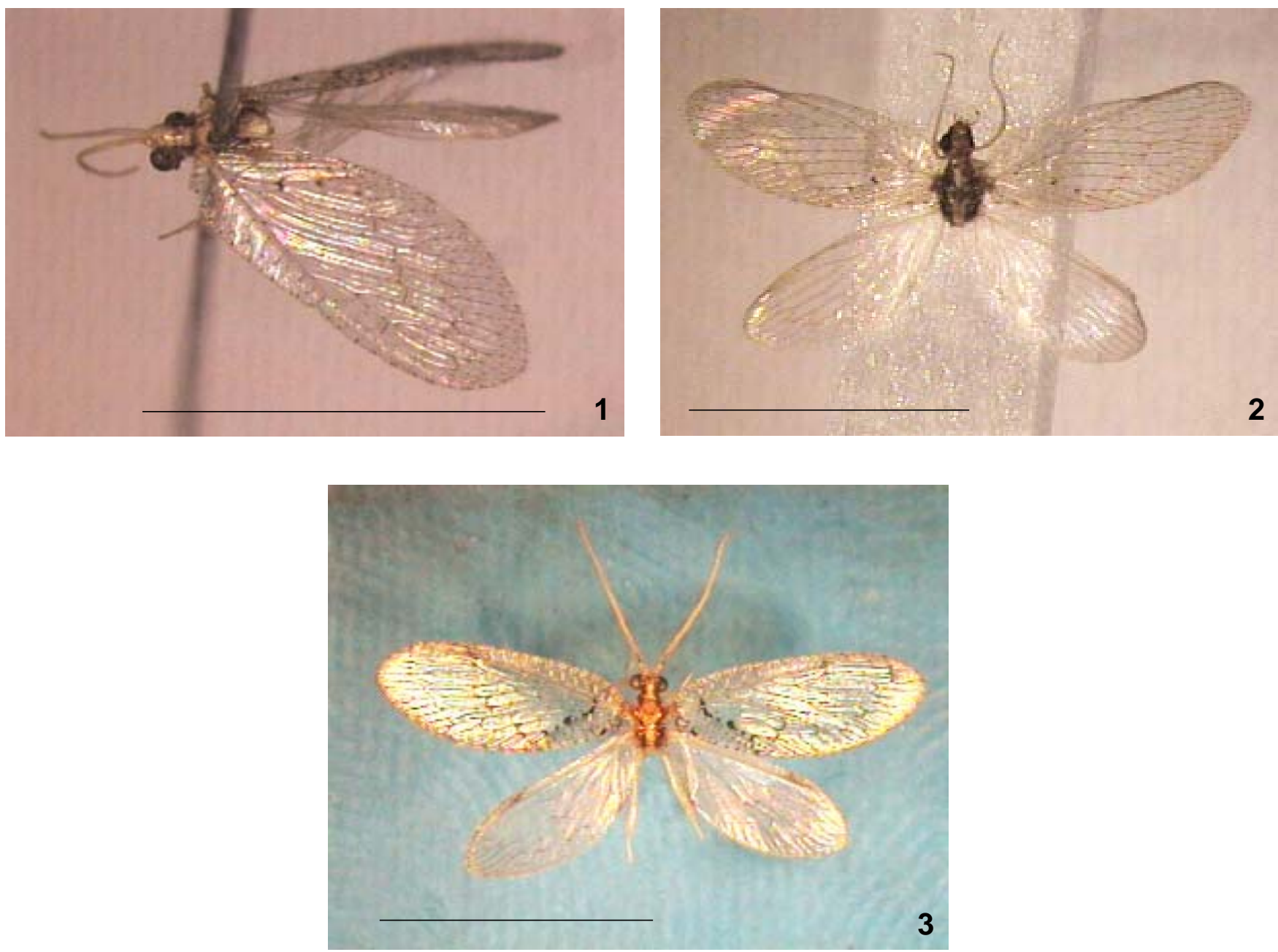

Figs. 1-3. 1, Hemerobius bolivari Banks, 1910; 2, H. domingensis Banks, 1941; 3, H. gaitoi Monserrat, 1996. Escala=0,7mm.

nono e décimo tergitos cobertos por microtríquias, com cerdas longas, esparsas, inseridas em pequenas protuberâncias do tegumento; décimo tergito bipartido com maior número de cerdas longas na margem interna, callum cerci com 13 tricobótrias.

Genitália masculina. Nono tergito estreito em vista dorsal e lateral, sem projeções, com margens anterior e posterior paralelas à margem anterior do ectoprocto; nono esternito semicircular em vista ventral; ectoprocto (Fig. 12) subtriangular em vista lateral, arredondado posteriormente, margem interna com projeção apical digitiforme. Gonarco (Figs. 13-15) delgado, placas laterais subovóides, margem dorsal em forma de "U" aberto, membrana acima dessa margem com sete gonosetas curtas e quatro longas; entoprocessos subcilíndricos, estrutura dupla, longa, fina, curvada para baixo, apicalmente afilada, cruzados no terço apical, margem basal larga em vista lateral (Fig. 15). Parâmeros (Fig. 16) pequenos, livres, arqueados em vista dorsal, com dentículo apical de forma triangular, margem basal alargada, situados lateralmente às placas laterais do complexo gonarco e acima do nono esternito. Hipândrio interno (Fig. 17) trapezoidal, largo, margem lateral anterior retorcida.
Comentários. H. domingensis distingue-se de $H$. bolivari por apresentar asas de formato diferente, veias mp-cu1 e cu1cu2 não coincidentes, margem dorsal do gonarco em forma de "U” aberto (em forma de "V" em H. bolivari) e entoprocessos cruzados no terço apical (paralelos em H. bolivari). Em um dos exemplares estudados as asas anteriores apresentam setor radial com quatro ramos e a margem dorsal do gonarco em forma de "U" aberto, com margens laterais e basal quase retas, formando ângulos internos próximos a $90^{\circ}$. Em um exemplar observou-se, através de microscopia eletrônica, a presença de entoprocessos cruzados próximo da linha mediana (Fig. 13), o que pode ser uma variação interespecífica ou uma modificação provocada pelo processo de dessecação para preparo do material para microscopia.

Segundo MonserRat (1996), H. domingensis é citada para Cuba e Republica Dominicana. Trata-se do primeiro registro de ocorrência de $H$. domingensis para o Brasil.

Material examinado. BRASIL. São Paulo: Ribeirão Preto, 1 macho, 26.XII.2001, R.I.R. Lara (IBSP). Paraná: Cascavel, 1 macho, 15.XI.1999, 1 macho, 17.XI.1999, 1 macho, 30.VI.1999, M.S.P. Leite (UNESP). 

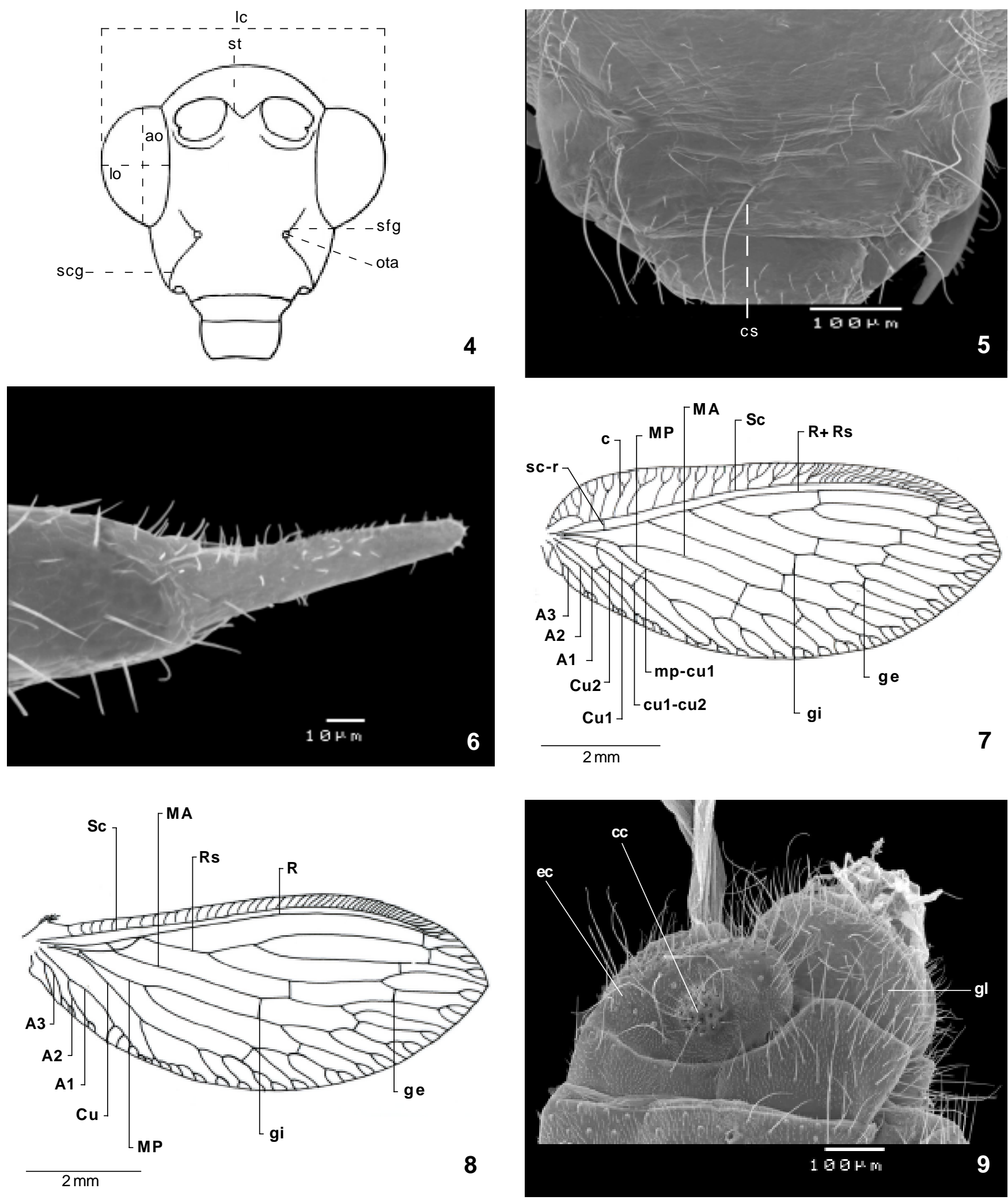

Figs. 4-9. 4. Cabeça, vista frontal (adaptada de OswaLd 1993): ao = altura do olho; lc = largura da cabeça; lo = largura do olho; ota = orifício tentorial anterior; scg = sutura clípeogenal; sfg = sutura frontogenal; st = sutura transtorular. Figs. 5-9. Hemerobius bolivari Banks, 1910. 5, detalhe do clípeo; 6, detalhe do $5^{\circ}$ palpômero maxilar; 7, asa anterior; 8, asa posterior; 9, ápice abdominal da fêmea, vista lateral; A1-A3 = veias anais; c = veia transversal costal; $\mathrm{cc}=$ callum cerci; $\mathrm{cs}=$ cerda sagital; $\mathrm{Cu}=$ veia cubital; $\mathrm{cu} 1-\mathrm{cu} 2=$ veia transversal; ec $=$ ectoprocto; ge = gradiforme externa; gi = gradiforme interna; gl = gonapófises laterais; $\mathrm{MA}$ = veia medial anterior; $\mathrm{MP}$ = veia medial posterior; $\mathrm{mp}$-cu1 = veia transversal; $\mathrm{R}=$ veia radial; $\mathrm{Rs}$ = setor radial; $\mathrm{Sc}=$ veia subcostal; $\mathrm{sc}-\mathrm{r}=$ veia transversal. 

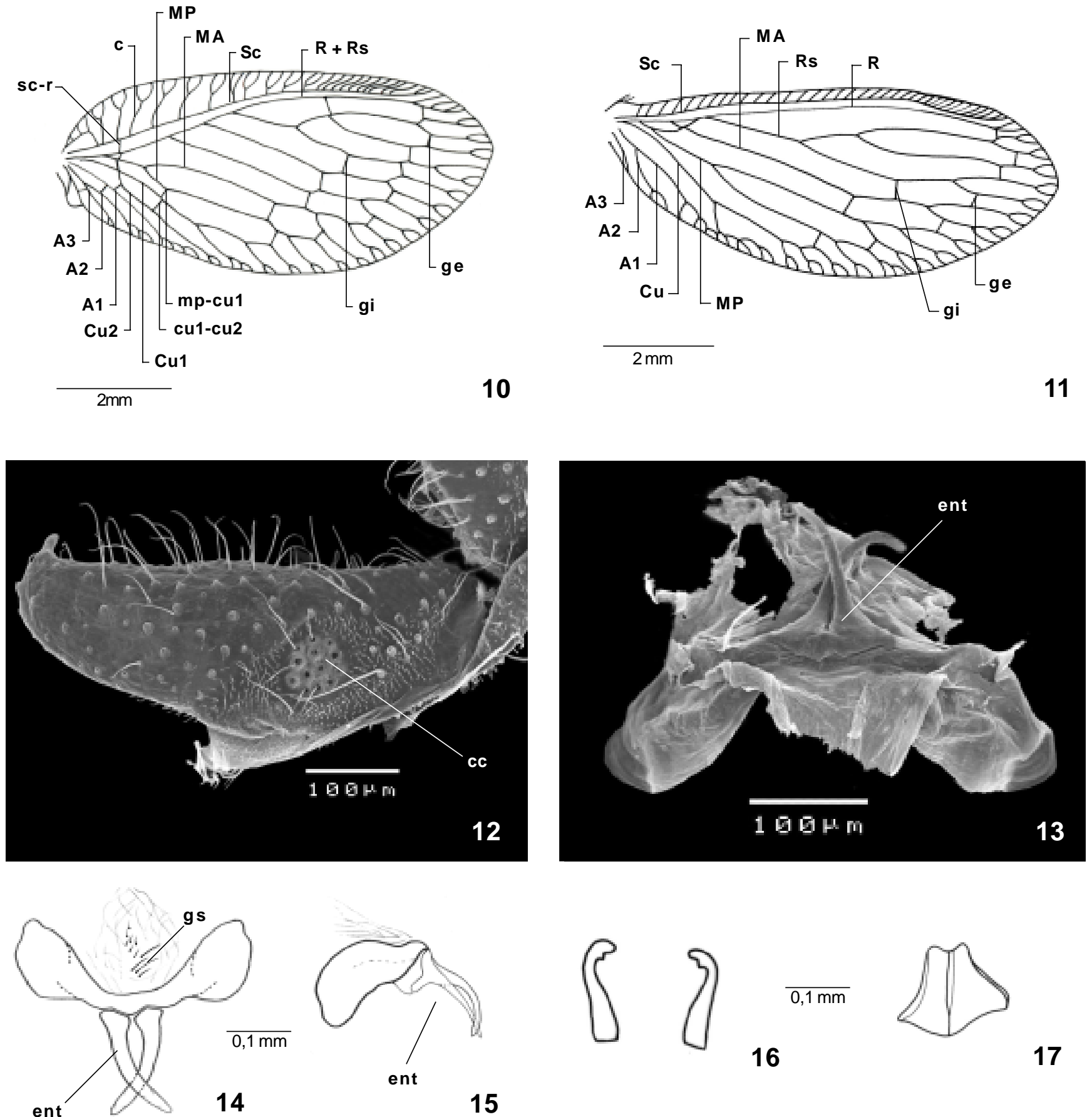

16

15

Figs. 10-17. Hemerobius domingensis Banks, 1941. 10, asa anterior; 11, asa posterior; 12, ectoprocto do macho; 13, 14, gonarco, vista dorsal; 15, gonarco, vista lateral; 16, parâmeros, vista dorsal; 17, hipândrio interno, vista dorsal; A1-A3 = veias anais; c = veia transversal costal; cc = callum cerci; $\mathrm{Cu}$ = veia cubital; cu1-cu2 = veia transversal; ent = entoprocessos; ge = gradiforme externa; gi = gradiforme interna; gs = gonosetas; $\mathrm{MA}=$ veia medial anterior; $\mathrm{MP}=$ veia medial posterior; mp-cu1 = veia transversal; $\mathrm{R}=$ veia radial; $\mathrm{Rs}=$ setor radial; $\mathrm{Sc}=$ veia subcostal; $\mathrm{sc}-\mathrm{r}=$ veia transversal.

Hemerobius gaitoi Monserrat, 1996

(Figs. 3, 18-24)

Coloração (Fig. 3). Cabeça amarelo-palha com manchas marrons; vértice amarelo-palha, com manchas marrons nas laterais e outra em forma de $\mathrm{V}$ na inserção de cada uma das antenas; dorso torácico com faixa meso-longitudinal amarelo- palha, marrom lateralmente; região postocular e genas marrons; olhos escuros, com reflexos metálicos; margem externa do escapo sombreada de marrom; terço basal do flagelo marrom e terço distal amarelo-palha sombreado de marrom; palpos maxilares e labiais marrons, exceto a extremidade apical do $5^{\circ}$ palpômero maxilar e $3^{\circ}$ palpômero labial, amarelo-palha; pernas amarelo-palha. Asas anteriores hialinas; veias 


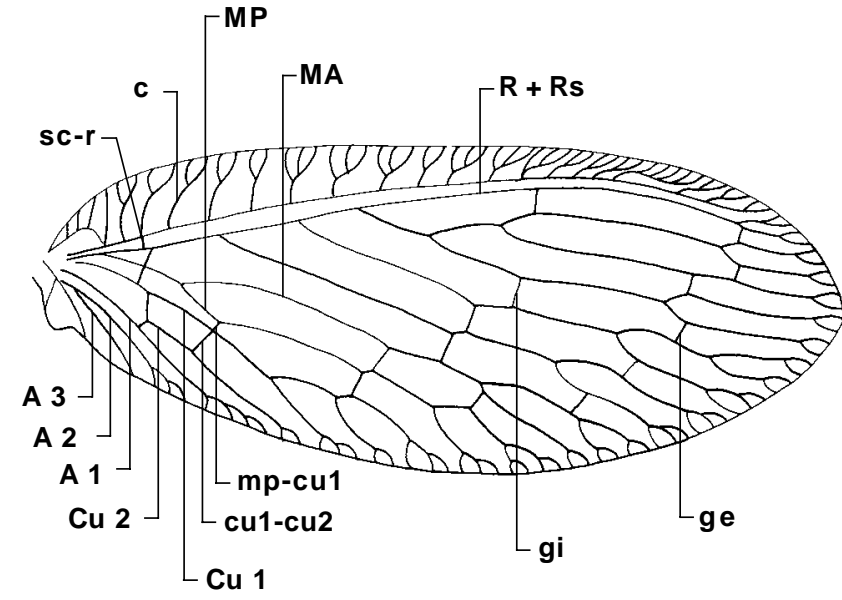

18

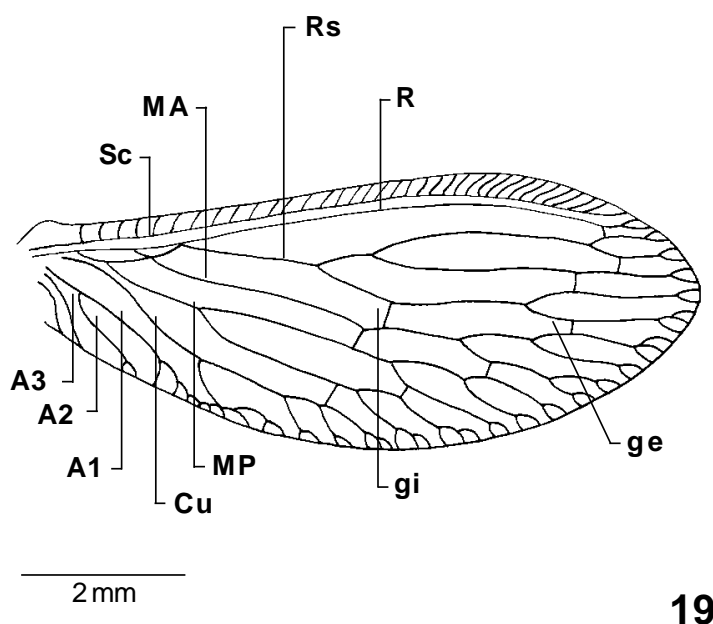

19

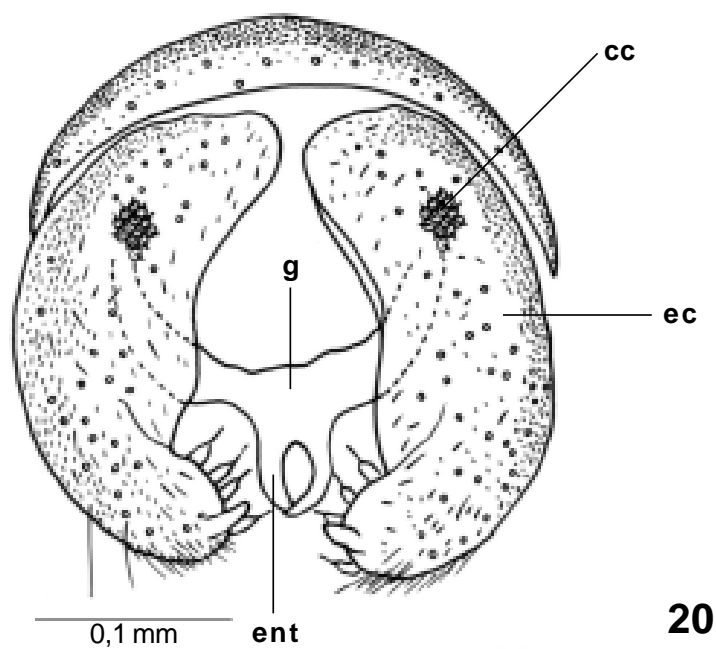

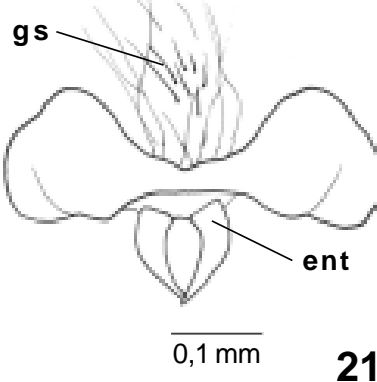

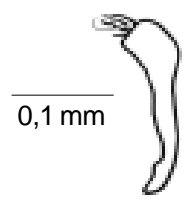

21

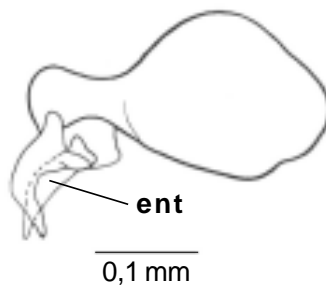

22

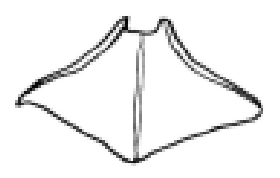

$\overline{0,1 \mathrm{~mm}}$

23

Figs. 18-24. Hemerobius gaitoi Monserrat, 1996. 18, asa anterior; 19, asa posterior; 20, ápice abdominal do macho, vista dorsal; 21, gonarco, vista dorsal; 22, gonarco, vista lateral; 23, parâmeros, vista dorsal; 24, hipândrio interno, vista dorsal; A = veia anal; c = veia transversal costal; cc = callum cerci; $\mathrm{Cu}=$ veia cubital; cu1-cu2 = veia transversal; ec = ectoprocto; ent = entoprocessos; g = gonarco; ge = gradiforme externa; gi = gradiforme interna; gs = gonosetas; $\mathrm{MA}=$ veia medial anterior; $\mathrm{MP}=$ veia medial posterior; $\mathrm{mp}$-cu1 = veia transversal; $\mathrm{R}=$ veia radial; $\mathrm{Rs}=$ setor radial; $\mathrm{Sc}=$ veia subcostal; sc-r = veia transversal.

transversais sc-r, mp-cu1 e cu1-cu2 marrons; três manchas circulares, marrons sobre $\mathrm{Cu} 1$; manchas marrons esparsas nas áreas cubital e anal; pterostigma indistinto; lóbulo jugal marrom. Asas posteriores hialinas; pterostigma marrom-claro. Asas anteriores e posteriores com veias longitudinais amarelo-palha intercaladas por áreas de coloração marrom e séries gradiformes marrom-claro.

Cabeça. 4,1 vezes mais larga que a largura do olho (lc/lo), marcada pelas suturas frontogenal, clípeogenal e transtorular. Vértice convexo, coberto anteriormente por microtríquias e com longas cerdas esparsas. Olhos proeminentes, hemisféricos, 1,9 vezes mais longos que largos (ao/lo). Ocelos ausentes. Antenas moniliformes; escapo achatado, 1,3 vezes mais longo que largo (ce/le); flagelo com cerdas abundantes, curtas. Orifício tentorial anterior visível na intersecção das suturas frontogenal e clípeogenal. Labro com margens látero-dorsais arredondadas. Genas lisas, com cerdas esparsas. Clípeo com dois pares de longas cerdas na margem distal e uma cerda sagital na região central. Palpo maxilar com cinco artículos, o quinto fusiforme com extremidade apical afilada, os demais, simples com cerdas longas, esparsas; gálea bi-articulada, artículo distal com pilosidade densa, curta; região apical da lacínia densamente pilosa. Palpo labial com três artículos; palpômeros simples, com cerdas longas e esparsas, exceto o terceiro que é semelhante ao quinto palpômero maxilar.

Tórax. Arqueado em vista lateral, coberto por microtríquias; pronoto e mesonoto densamente cobertos por cerdas longas, esparsas na pleura. Protórax: pronoto, 1,6 vezes mais largo que longo (lp/cp), com margens laterais arredondadas que cobrem parte dos escleritos laterais. Mesotórax: mesoscuto deprimido 
na região mediana. Metatórax: metascuto grande e transverso. Pernas com pilosidade densa e curta; procoxa alongada, cilíndrica, 0 ,8 vezes o comprimento do profêmur (cpc/cf); mesoe metacoxas curtas e cônicas; comprimento dos fêmures e tíbias semelhantes, à exceção do metafêmur que é 0,7 vezes o da metatíbia (cf/ct); tíbia anterior com um esporão apical; tíbias mediana e posterior com dois esporões; tarsos pentâmeros, pré-tarso com um par de garras laterais e um empódio mediano, em forma de almofada. Asas anteriores e posteriores com macrotríquias sobre as veias longitudinais, transversais da área costal e nas margens; membrana densamente coberta por microtríquias. Asa anterior (Fig. 18) 2,2 vezes mais longa que larga (caa/laa); área costal proximal ampla, 0,2 vezes a largura máxima da asa (ac/laa); veia umeral recorrente definida; veias transversais costais bifurcadas; uma veia transversal sc-r preestigmal; R e Rs em tronco único (R + Rs) com três ramos; duas séries gradiformes (três internas e seis externas); MP unida à Cu1 por uma veia oblíqua, curta; duas veias transversais mpcu1 localizadas apicalmente a esta fusão; mp-cu1 e cu1-cu2 coincidentes; célula cubital aberta; três veias anais ramificadas; lóbulo jugal distinto. Asa posterior (Fig. 19) 0,9 vezes o comprimento da anterior (cap/caa), 2,5 vezes mais longa que larga (cap/lap); área costal reduzida com veias transversais simples; subcostal espessa; R e Rs não coalescentes, tocandose por meio de uma veia transversal; duas séries gradiformes (duas internas e cinco externas); MA unida à R por uma transversal oblíqua.

Abdome. Tergitos e esternitos transversos; extremidade apical coberta de cerdas longas, esparsas, inseridas em pequenas protuberâncias do tegumento; décimo tergito bipartido, callum cerci com 13 tricobótrias.

Genitália masculina (Fig. 20). Nono tergito transverso, estreito em vista dorsal, com margens anterior e posterior paralelas à margem anterior do ectoprocto; nono esternito semicircular em vista ventral; ectoprocto alongado, arredondado posteriormente, margem interna apicalmente com projeção digitiforme e quatro setas modificadas, largas basalmente e com extremidade fina. Gonarco (Figs. 21,22) delgado, placas laterais ovóides, alargadas, margem dorsal em forma de "U" aberto, membrana acima dessa margem com sete gonosetas; entoprocessos robustos, curtos com extremidade apical aguda, margem basal larga em vista lateral (Fig. 22), curvados para baixo em sua porção mediana, com extremidades se tocando apicalmente. Parâmeros (Fig. 23) pequenos, livres, porção basal alargada com dentículo apical de forma triangular, situados lateralmente às placas laterais do complexo gonarco $\mathrm{e}$ acima do nono esternito. Hipândrio interno (Fig. 24) trapezoidal, largo, margens laterais subparalelas na metade posterior e divergente na anterior.

Comentários. H. gaitoi distingue-se de $H$. bolivari por apresentar coloração cefálica, antenal e das asas distintas, o ectoprocto mais curto e estreito, a margem dorsal do gonarco em forma de "U" aberto e os entoprocessos robustos, dobrados para baixo em sua linha média. MonsERRAT (1996) ao comparar $H$. gaitoi com $H$. cubanus afirma que a segunda espécie apresenta o ectoprocto mais curto e largo, margem interna com 10-11 setas grossas; o gonarco mais largo e os entoprocessos mais curtos, robustos e curvados que em outras espécies do grupo bolivari. Hemerobius gaitoi foi descrita da Costa Rica e está registrada para o México, Republica Dominicana, Guatemala, Venezuela, Brasil e Equador (MonserRat 1996).

Material examinado. BRASIL. São Paulo: Ribeirão Preto, 1 macho, 1.II.2001, R.I.R. Lara (IBSP).

Agradecimentos. Ao Dr. Enrique González Olazo, da Fundácion Miguell Lillo, San Miguel de Tucumán, Argentina, pela identificação dos exemplares de $H$. bolivari.

\section{REFERÊNCIAS}

Carpenter, F. M. 1940. A revision of the Neartic Hemerobiidae, Berothidae, Sisyridae, Polystoechotidae and Dilaridae (Neuroptera). Proceedings of the American Academy of Arts and Sciences 74(7): 193278.

Chagas, E. F. das; S. Silveira Neto; A. J. B. P. Braz; C. P. B. Mateus \& I. P. Coelho. 1982. Flutuação populacional de pragas e predadores em citros. Pesquisa Agropecuária Brasileira 17(6): 817-824.

González Olazo, E. V. 1987. Los neuropteros asociados con los cultivos citricos de la provincia de Tucumán y descripción de una nueva especie de Nomerobius (Hemerobiidae). CIRPON, Revista de Investigación 1-4: 37-54.

Kevan, D. K. McE. \& J. Klimaszewski. 1987. The Hemerobiidae of Canada and Alaska. Genus Hemerobius L. Giornale Italiano di Entomologia 16(3): 305-369.

MonserRat, V. J. 1990. A systematic checklist of the Hemerobiidae of the world (Insecta: Neuroptera), p. 215-262. In: M. W. MAnsell \& H. Aspöck (eds.). Advances in Neuropterology. Proceedings of the Third International Symposium on Neuropterology. Pretoria, 298 p.

MonserRat, V. J. 1996. Revision del genero Hemerobius de Latinoamerica (Neuroptera, Hemerobiidae). Fragmenta Entomologica 27(2): 399-523.

Penny, N. D. \& V. J. Monserrat. 1983. Neuroptera of the Amazon basin. Part 10-Hemerobiidae. Acta Amazonica 13(5-6): 879-909.

Perioto, N. W.; R. I. R. Lara; J. C. C. Santos \& T. Silva. 2000. Utilização de armadilhas de Moericke em ensaios de seletividade de inseticidas em himenópteros parasitóides. Arquivos do Instituto Biológico 67(supl.): 93.

Santos Rojo, F. M. \& M. A. Marcos-Garcia. 1998. Presence of predatory lacewing (Neuroptera: Chrysopidae, Hemerobiidae) on Mediterranean crops. Acta Zoologica Cracoviensia 41(2): 173-181.

Stelzl, M. \& D. Devetak. 1999. Neuroptera in agricultural ecosystems. Agriculture, Ecosystems and Environment 74(1-3): 305-321.

Szabó, S. \& F. SzentKirályi. 1981. Communities of Chrysopidae and Hemerobiidae (Neuroptera) in some apple-orchards. Acta Phytopathologica Academiae Scientiarum Hungaricae 16(12): 157-169.

TJeder, B. 1954. Genital structures and terminology in the order Neuroptera. Entomologiske Meddelelser 27: 23-40.

TJEDER, B. 1961. Neuroptera - Planipennia. The lacewings of Southern Africa 4. Family Hemerobiidae, p. 296-408. In: B. Hanstrom; P. BRINCK \& G. RudEBEC (eds.). South African Life. Stockholm, Swedish Natural Science Research Council. 